Deep-sea Soundings and Deep-sea Thermometers

We feel sure you will not deny us space in your valuable periodi. cal, when we tell you that, however unconsciously on your part, you, as well as other scientific authorities, are the means of doing us injustice and much professional injury, by the frequent allusions to the so-called Casella-Niller Thermometer, now used in deep-sea investigations. We are certain that we have only to call your attention to the real facts of the case for you to set the matter right before your readers.

x. We beg to state that in the year 1857 we invented, made, and supplied the Meteorological Department of the Board of Trade with upwards of fifty instruments of this description.

2. This thermometer we called the Double Bulb Deep Sea Thermometer, and a notice of it was published in the first number of the Neteorological Papers for the year 1857 .

3. This thermometer, identical in every respect (except in its size), has been, after a lapse of some twelve years, re-intented and ushered before the scientific world with all the prestige of having a paper read upon it by the Vice-President of the Royal Society, Dr. Miller, who declared that he had just invented the instrument, in which task (of inventing an instrument well-known to all leading instrument makers, and Mr. Casella among the number) the learned doctor says he was assisted by MIr. Casella (See Proceedings of the Royal Society, No. Ir 3, page 482 ).

4. Annexed is an extract from Dr. Miller's paper describing the instrument, and by its side we give an extract from a treatise published by us in the year 1864 , called "A Treatise on Meteo. rological Instruments."

Extract from "The Pro. ceedings of the Royal Society," vol. xvii. page 483 . Paper read June 3, 1869 , by Dr. Miller.

"The expedient adopted for protecting the thermometer from the effects of pressure consisted simply in enclosing the bulb of such a Six's thermometer in a second or outer glass tube, which was fused upon the stem of the instru. ment.

"This outer glass tube was nearly filled with alcohol, leav. ing a little space to allow of variation in bulk due to expansion.

"The spirit was heated to displace part of the air by means of its vapour, and the outer tube and its contents were sealed hermetically."

5. We lezve your readers to draw their own conclusions as to the similarity of the two instruments. Dr. Miller, when we called his attention to the fact of our prior claim, stated that he was not aware of the existence of our instrument, and we freely acquit Dr. Miller of conscious plagiarism, but we cannot omit to state, at the same time, that at the date at which Dr. Miller's paper was read, any scientific instrument maker worthy of the name was fully acquainted with our arrangement.

6. In order to prove what we thought of our instruments and as to their fitness for the purpose they were intended, when we were written to by the Mleteorological Committee, three or four years ago, to produce a thermometer to be submitted to them for approval, we replied that we had already produced the only thermometer which in our opinion would answer the purpose, and that the thermometer was well known to them; we also sald we were ready to make that instrument smaller, or larger, but that we could not possibly produce a better one.

Ilolborn Viaduct, E.C.

HY. NegretTI \& ZaMbra October 14

\section{Settle Caves Report}

In your abstract of the "Report of the Committee for explorin the Victoria Cave at Settle, by WV. Boyd Dwakins, F.R.S." vol. viii. p. $47^{6}$, are the following sentences. "The exact age of theCaveearth is a matter of dispute. Mr. Tiddeman from the physical evidence alone regards it as preglacial, or rather as older than the great ice-sheet of that district.
Now it is true that in the spring of 1871 , at a meeting of the Settle Caves Committee, I suggested the probability of the beds of lower Cave-earth in the Victoria Care being of preglacial age from the physical evidence in the cave alone; but at a committee meeting at Settle soon after I laid much stress upon the impossibility of any animals, existing before the time of the Icesheet, having their remains preserved in the open country, although it was very likely that they might be found sealed up in sheltered caves. Acting on this idea the committec, notwithstanding some opposition, fortunately deternined upon continuing their researches, and the result was the interesting discovery of the older mammals

May I be permitted to cite the following paragraph from the Geolosical Magazine of Jan. 1873, to show that I do not rely upon the physical evidence in the care alone as determining the age of the lower cave-earth, although I confess that evidence, to my mind, is almost conclusive. "Perhaps one of the strongest pieces of evidence that the older cave mammals mentioned lived in this district only at a time previous to the great icc-sheet is, that so far as we know the remains of none of them (except of Cerzus elaphus, which ranges from the Forest-bed to the present day) have been found in any of the Post-glacial deposits in this district. Though so common in the river-gravels in the MIidland and Southern counties, they are never found except in caves until we get much farther south or ea:t. Leeds, I believe, is the nearest locality where they occur. This would seem to imply that their remains were wiped off the area by the great ice-sheet which occupied what is now the Irish Sea and its tributary riversystems, and only left in the shelter of caves to which it could have no direct access. Brown bear, horse, red deer, reindeer, megaceros, the more modern Bovidx, and other more recent forms are not uncommon in the Post-glacial beds; but.the older cave mammals seem conspicuous only by their absence."

Clapham, Lancaster, Oct. 6

R. H. TIDDEMAN

\section{Carbon Battery Plates}

MIR. T. WV. FLETCHER will obtain what he requires from the India Rubber, Gutta Percha, and Telegraph Works Cu., No. 10, Cannon Street, E.C.

I have 12,000 Carbons, or as we call them Graphite Plates, at work at this moment, and for some years past have obtained them solely from the above Company.

Tunbridge, Oct. I4

Cilarles V. Walker

\section{ASTRONOMICAL ALMANACS*}

\section{III.-Foundation of the Nautical Almanac}

DURING his voyage of $176 I$ to the island of Saint Helena, for the purpose of observing the transit of Venus, Maskelyne, like La Caille, investigated the methods for determining longitudes at sea, and on his return, in "The British Mariner's Guide" (I763), proposed to adopt the plan of an almanac sketched by the French astronomer. There existed at this time in England a commission instituted by George III. for the discovery of longitudes at sea; $t$ it was a body almost analogous to the present French "Bureau des Longitudes." Maskelyne took many steps to induce this Commission to approve of his proposal ; and, at the same time, he commissioned several ship-captains to put it to the test: Their reports confirmed his assertions, and on February 9, 1765 , Naskelyne presented to the Commissioner of Longitude a detailed report, in which, besides a complete exposition of the method and plan of a nautical almanac, he gave from the entries in the log-books the result of this new method. The proposition of the wise abbe was adopted, and Maskelyne was entrusted with the calculation and publication of the "Nautical Almanac

* Coniuued from p. $35^{2}$

Act of Parliament or the discovery of longitude at Sea, and for examining, trying, and judging of all Proposals, Extric and Pacific Oceans, attempts to fid a Northern Passase be

It approach the Northern Pole. the Sun and Moon, by Tobias Maycr: London, 1770 . Published by order of the Commissioner of Longitude. 
and Astronomical Ephemeris." The Commissioners did more; they ordered the printing of the Tables of the Moon, left by Tobias Mayer, according to which the lunar distances were to be calculated. At the same time parliament voted a sum of 3,000 l. to the widow of the astronomer of Göttingen, and a sum of $300 l$. to Euler, for having furnished to Mayer the theorems which he used to construct his theory.*

The first volume of the "Nautical Almanac" is concerned with the year 1767 , and appeared in 1766 . Although infinitely superior to the "Connaissance des Temps" for 1767 , this publication is far from the perfection which it has since attained. Its object is two-fold, but not welldefined; it contains much information useless to the astronomer, and many things besides which the mariner could dispense with. There is first a calendar with the aspects of the planets; then a solar table giving for each day the longitude of the sun at noon, calculated to $\frac{1}{10} \overline{0}$ of a second ; the right ascension of the sun in time to ${ }_{30}$ of a second, his declination to a second, and the equation of the time; next follow the eclipses of the four first satellites of Jupiter; then tables of the planets, giving the longitude (to a second) and the latitude (to a minute), heliocentric and geocentric, the declination (to a second), the hour of the passage of the meridian (to a minute), every third day for Mercury, and every sixth day for the other planets. The table following gives, for every day from noon to midnight, the longitude (to the $\frac{1}{10 \sigma}$ of a second) and the latitude (to a second) of the moon, her right ascension and declination from noon to midnight, as well as her apparent semi-diameter and horizontal parallax. Then follow the distances calculated for every three hours, of the moon from the sun and from a certain number of stars of the first magnitude, and lastly the configuration of the satellites of Jupiter for every day in the year, at 5.30 P.M. The work is completed by detailed and well-written instructions, telling the signification and use of the various tables contained in the volume.

The calculations are, moreover, made with an amount of care far greater, according to Lalande, than was ever bestowed on the "Ephémerides." Each article was calculated separately by two persons and verified by a third calculator. In the case of the longitudes, latitudes, right ascension, declination, semi-diameter, and parallax of the moon, these were calculated by one person for noon and another for midnight, and afterwards verified by the mean of the differences which were carried as far as the fourth order.

Some years later, in 1772 , three English astronomers, Lyons, Parkinson, and Williams, published some exceedingly convenient tables, entitled, "Tables for correcting the apparent Distance of the Moon and a Star from the Effects of Refraction and Parallax" (Cambridge, 1772), by the aid of which ten minutes sufficed to calculate an observation of distance between the moon and a star, and therefrom to deduce the longitude. The use of the lunar distances became from that time a great convenience. It was in the same year, 1772 , that Lalande transferred into the "Connaissance des "Temps" for 1774 the calculations of the lunar distances copied in the "Nautical Almanac," "not having," said he, "either the leisure to do it myself, nor the means which the Commission of Longitude of London furnished to the Astronomer-Royal Maskelyne, for maintaining calculators, whose work he had only to superintend and verify." The introduction of these lunar distances doubled the value of the "Connaissance des Temps," which became a work useful at once to astronomers and mariners.

\section{Foundation

$$
\text { of the Berlin "Astronomisches }
$$

This same year, I774, witnessed the appearance of a * Fifty years later, another parliament authorised the printing of the new astronomer a sum of $1,000 l$. by way of national recompense. great number of publications analogous to the Connais. sance des Temps and the Nautica! Almanac, all intended to regulate the publication of the Ephemerides, which. in nearly all countries astronomers published at different times. Of these we shall mention the "Jahrbuch" of Berlin, the "Ephemerides" of Vienna, and those of Milan.

The idea of the "Berliner Astronomisches Jahrbuch" originated with Lambert. Born August 29, 1728, at Mulhouse, then a free town of Alsace, of parents who kept a small tailor's shop, Lambert reccived a very incomplete elementary education, which he afterwards supplemented by assiduous labour and persevering determination. In 1748 Count Pierre de Solis entrusted Lambert with the education of his children; this was an opportunity of which he knew how to take advantage. He found in the Chateau of Coire, the abode of this nobleman, an exceedingly rich library, by means of which he not only completed his imperfect education, but from which he drew the elements of one of his finest works, the "Dissertation on the remarkable Properties of Light." Shortly after, in 1763 , the restraints to which Protestants were subjected in France, and in particular the law which prohibited them from exercising any public functions, induced him to yield to the invitations of Frederick the Great ; Lam. bert went to live at Berlin, and became, in I 764 , a pensionnaire of the Royal Academy of Prussia. France thus lost one of her scientific glories; for, not only was Lambert a distinguished astronomer, $\}$ but pre-sminently remarkable for the universality and extent of his attainments.*

Long before the time to which we refer there had appeared at Berlin Astronomical Ephemerides; the first, due to the astronomer Grischow, date from I 749; it is the "Calendarium ad annum I749 pro meridianum Berolinense cum approbatione Academica regia Scientiarum et elegantiarum litterarum Borussia." They were carried on by Grischow until 1754, and suffered afterwards many interruptions. It was these Ephemerides which Lambert undertook to revive. According to the plan which he proposed to the Academy of Bcrlin, each volume of the "Jahrbuch" would appear two years in advance and consist of two parts. One part was devoted to the astronomical ephemerides (Prussia not then having any marine, Lambert had not to trouble himself with nautical ephemerides) and so disposed that it could essily serve for a place of different latitude; the other forming a collection of all the news concerning the astronomical sciences (observations, remarks, and problems). Lambart also proposed to collect, in another work, all the tables serving either for the calculation of the ephemerides or for other astronomical calculations.

The proposal of Lambert having been adopted, an astronomer who was afterwards director of the Berlin observatory, and whose reputation became universal, $J$. El. Bode, was entrusted, under the direction of Lambert and the nominal superintendence of the Academy, with the numerous calculations which the publication of these Ephemerides necessitated. The first volume appeared in I774, under the title of "Berliner astonomisches Jahrbuch für 1776 , unter aufsicht und mit Genehmhaltung der königlichen Academie der Wischenschaften verfertigt und zum Drucke befördert."

Lambert had the direction of the "Jahrbuch" for only a very short time; death came soon after to deprive Science of one of her most ardent worshippers. Nevertheless his initiative, though of short duration, "was successful, and from its first appearance, the work which he founded progressed more notably than those which preceded it.

At the same time also appeared the Ephemerides of Milan,- "Effemeridi artronomiche per l'anno 1775, calculate pol meridiano di Milano, del abbe Angelo de

* His most important astronomical work is entitled "Insigniores Orbita Cometarum Proprietałes." 
Cesaris." It was also the first volume of a series of ephemerides which have been since continued without interruption.

In 1799 the publication of the Portuguese ephemerides commenced - "Ephemerides astronomicas calculadas para o meridiano Observatorio nacional de universidade de Coimbra, para uso do mesmo Observatorio, e para o da navegacao Portugueza."

Lastly, in 1756 , appeared the ephemerides of Vienna :"Ephemerides astronomica anni 1757 , ad meridianum Vindobonensem jussu Augustorum calculis a Mlaximiliano Hell. Casario regio astronomo et Mechanicus experimentalis professore publico et ordinis," which were continued by Triesmecker. The Ephemerides of Vienna were constructed upon the model of the Abbé de la Caille, much more than upon that of the Connaissance des Temps. MIorcover, at this period, the Ephemerides of La Caille were almost exclusively employed by French astronomers.

(To be continued.)

\section{THE BRIGHTON AQUARIUM}

$\mathrm{N}$ accordance with an intention entertained previous to $I$ resigning the tenure of my office as Curator to the Brighton Aquarium, I propose to give a brief outline of the plan of construction and general system of arrangements obtaining in that institution.

The Brighton Aquarium, while emulated by several buildings of a similar nature, in different parts of the kingdom and on the Continent, still holds its own in being on a scale of magnitude hitherto unsurpassed, more than one of its tanks, in illustration of this, being of sufficient size to accommodate the evolutions of porpoises and other small Cetacex. The architect and originator of the undertaking, Mr. Edward Birch, well known as the engineer of the new picr at Hastings, entertained the idea of constructing this Aquarium as long agro as the year 1866 when visiting the one on a small scale then existing at Boulogne; Brighton was selected as a site on account of its proximity to the sea-coast and its great popularity as a place of resort. The works were commenced in the autumn of the year 1869 , but owing to various interruptions the building was not formally thrown open to the public until August 1872 , the ceremony taking place during the week in which the members of the British Association honoured Brighton as their place of meeting.

The area occupied by the Brighton Aquarium averages 715 fect in length by 100 feet in width, running east and west along the shore line between the sea and the Marine Parade; the principal entrance is at the west end facing the castern angle of the Royal Albion Hotel. The building internally is divided into two corridors separated from one another by a fernery and considerable interspace. The approach to the first or Western corridor is gained through a spacious entrance-hall supplied with readingtables, and containing between the pillars which support the roof portable receptacles of sea-water for the display of small marine specimens that would be lost to sight in the larger tanks.

The tanks for ordinary exhibition commence with No. I on the left side of the western corridor, and, as shown in the ground-plan, follow in consecutive order round the two corridors, the last, No. $4 \mathrm{r}$, immediately facing No. $\mathrm{I}$. The smallest of these tanks measures in feet long by 10 feet broad, and is capable of holding some 4,000 gallons of water, while the largest, No. 6 , in the western corridor, and the subject of the accompanying engraving, presents a total frontage, including the two angles of 130 feet, with a greatest width of 30 feet, and contains no less than yo,000 gallons. Every gradation of size occurs between these two extremes, the depth of the water in all ranging from 5 to 6 feet. Supplementary to the foregoing, a series of half-a-dozen shallow octagonal table-tanks occupies a portion of the interspace between the two corridors, these being especially adapted for the exhibition of animals such as starfish, anemones, and others seen to best advantage when viewed perpendicularly through the water. Flanking one side of this same interspace are several ponds fenced off for the reception of seals and other amphibious mammalia and larger Reptilia, while at its further or eastern extremity artistic rock-work runs to a height of 40 feet, thickly planted with chroice ferns and suitable exotic plants, and broken in its course by a picturesque waterfall and stream. Tanks 12 to 17 in the eastern corridor, in addition to the stream and basin beneath the waterfall, are set apart for the exclusive exhibition of fresh-water fish, the remaining tanks being devoted to marine species. The bulk of water thus utilised in the fresh and sea-water tanks collectively amounts to 500,000 gallons, and in addition to this several smaller store tanks in the Naturalists' Room, adjoining the eastern corridor, afford accommodation for reserve stock, or for new arrivals before their display to public view.

The style of architecture dominant throughout the building is Italian and highly ornate, the arched roof of the corridors being groined and constructed of variegated bricks, supported on columns of Bath stone, polished serpentine marble, and Aberdeen granite; the capital of cach column is elaborately carved in some appropriate marine device, while the floor in correspondence is laid out in acrostic tiles. The divisions constituting the fronts of the tanks are composed each of three sheets of plate glass, each plate having a thickness of one inch, and measuring six feet high by three feet wide, separated from one another and supported centrally by upright massive iron mullions; in the smallest tanks the front is represented by but one of these divisions, while that of the largest, No. 6, consists of as many as eleven. Among other conspicuous structural features of the aquarium demanding notice are the huge masses of rock cntering into the composition of the tanks and fernery. Part of these are composed of porous tufa brought from Derbyshire, while the remaining and greater portion presents the appearance at first sight of old Red Sandstone of the Devonian epoch. This latter, however, is entirely artificial, being built up of smaller nondescript fragments, faced with cement and coloured sand, though so true to Nature have the boulders been fashioned and stratigraphically arranged, that more than one eminent geologist has been deceived by their aspect, and it is difficult in looking into the larger tanks to get rid of the impression that some of the miniature picturesque coves characteristic of the Devonshire coast have been transported bodily to Brighton.

The system adopted at the Brighton Aquarium for continually renewing the supply of oxygen necessary for the well-being of the animals agrees with that followed at Berlin, streams of compressed air being constantly forced into the tanks through vulcanite tubes carried to the bottom of the water, and each tank being fitted with a greater or less number of these tubes according to its size. Following the same principle there is no true circulation, each tank being distinctly independent and the same water rcmaining in it perpetually unless required to be changed on account of turbidity, an accident such as the cracking of a front glass, or for altering the arrangement of the inhabitants. In such cases the tanks are refilled from four large reservoirs situated beneath the corridors, holding in aggregate a quantity approximating but not exceeding that contained in the tanks above, and into which the water is first pumped by a six-horse power centrifugal engine direct from the sea, and thence conveyed by the same force to the tanks, through a main extending round the building.

The system above described, while practical in aquaria at the seaside, where the supply of water is unlimited, does not answer inland, as exemplified in the decadence, 